\title{
Depth Profiles of Absorbed Hydrogen in Ni-Nb-Zr Amorphous Alloy Ribbons by Glow Discharge Optical Emission Spectroscopy
}

\author{
Rie Y. Umetsu ${ }^{1}$, Mikiko Saito ${ }^{2}$, Toshio Sasaki ${ }^{1,2}$, Tetsushi Sekiguchi², Jun Mizuno², \\ Hiroshi Kawarada ${ }^{2}$ \\ ${ }^{1}$ Institute for Materials Research, Tohoku University, Sendai, Japan \\ ${ }^{2}$ Institute for Nanoscience \& Nanotechnology, Waseda University, Tokyo, Japan \\ Email: ${ }^{*}$ rieume@imr.tohoku.ac.jp
}

Received 27 October 2014; revised 16 November 2014; accepted 28 November 2014

Copyright (C) 2014 by authors and Scientific Research Publishing Inc.

This work is licensed under the Creative Commons Attribution International License (CC BY).

http://creativecommons.org/licenses/by/4.0/

(c) () Open Access

\section{Abstract}

Depth profiles of absorbed hydrogen introduced by electrochemical charging and light elements were analyzed in Ni-Nb-Zr-H amorphous alloy ribbons using a glow discharge optical emission spectrometer. It was clarified that the absorbed hydrogen was comparatively well-distributed on the sample surface and that the content of the hydrogen decreased with increasing depth from the surface. That is, the amount of absorbed hydrogen on the surface was about 17 at $\%$, while that inside the specimens decreased to several atomic percent. The depth profiles of the hydrogen which were close to the surface were slightly different between those on the roller side and those on the free side in the melt-spun ribbon. The difference is thought to originate from the existence of oxygen impurity on the surface and from the difference of the $\mathrm{Zr}$ content.

\section{Keywords}

Amorphous Ribbon, Hydrogen Absorption, Glow Discharge Optical Emission Spectroscopy, Depth Profile

\section{Introduction}

It has been known that Ni-based bulk metallic glassy alloys indicate high thermal stability, ultra-high strength, good ductility and excellent corrosion resistance [1] [2]. In addition of comparatively low material cost, Nibased bulk metallic grassy alloys are thought to be promising candidates for engineering materials. The Ni-Nb-

\footnotetext{
${ }^{*}$ Corresponding author.
}

How to cite this paper: Umetsu, R.Y., et al. (2014) Depth Profiles of Absorbed Hydrogen in Ni-Nb-Zr Amorphous Alloy Ribbons by Glow Discharge Optical Emission Spectroscopy. Open Journal of Metal, 4, 112-119. 
Zr ternary alloy system has been known to form an amorphous phase in a wide concentration region by rapid quenching, and furthermore, grassy alloys were also synthesized in the range of 50 to 70 at\% Ni, 5 to 35 at\% Nb and 5 to 45 at\% $\mathrm{Zr}$ [3]. Some interesting properties of this system have been intensively investigated. Excellent hydrogen permeability in melt-spun amorphous $\left(\mathrm{Ni}_{0.6} \mathrm{Nb}_{0.4}\right)_{50} \mathrm{Zr}_{50}$ alloy exceeding that of Pd has been reported by Yamaura et al. [4] [5], and mechanical properties of hydrogen absorbed amorphous ribbons have also been investigated by Kawashima et al. [6]. Recently, Fukuhara et al. have reported very unique electrical transport properties, such as super conductivity, electron avalanche behaviors and the Coulomb-blockade oscillations, in hydrogen absorbed amorphous ribbons of $\left[\left(\mathrm{Ni}_{0.6} \mathrm{Nb}_{0.4}\right)_{1-x / 100} \mathrm{Zr}_{x / 100}\right]_{100-y} \mathrm{H}_{y}(30<x<50,0<y<20)$ [7] [8]. They have pointed out that a local structure exists and that the localization effect of the hydrogen outside and/or inside spaces of distorted icosahedral $\mathrm{Zr}_{5} \mathrm{Ni}_{5} \mathrm{Nb}_{3}$ clusters plays important roles in their various electrical transport properties.

In our previous investigations, we reported that the amount of hydrogen absorbed by electrochemical charging in a $\mathrm{Ni}_{36} \mathrm{Nb}_{24} \mathrm{Zr}_{40}$ amorphous alloy ribbon can be controlled by changing the current density [9]. By systematic investigations, it was clarified that the magnitude of the temperature coefficient of the resistivity increased with an increase of the absorbed hydrogen in amorphous ribbons and that the electrical resistivity depended on time, that is, the absolute value of the electrical resistivity increased gradually with showing two-steps increasing. It has been thought that such behavior is due to the migration of hydrogen from the sample surface. Therefore, it is necessary to analyze the behavior of the hydrogen as well as the direction of the depth in the amorphous alloy ribbon in order to clarify the previously reported behavior of the unique electrical resistivity. In the present study, we analyzed the content of light elements as well as details of the composition of the constituent elements with the depth of the ribbon specimens of $\mathrm{Ni}_{36} \mathrm{Nb}_{27} \mathrm{Zr}_{37}$ alloy containing absorbed hydrogen introduced by electrochemical charging.

\section{Experimental Procedures}

Mother alloy of Ni-Nb-Zr was prepared by arc melting in an argon atmosphere and amorphous ribbons were made by a single roller melt-spinning technique. The roll speed was about $25 \mathrm{~m} / \mathrm{s}$. The thickness and width of the fabricated ribbon were $64 \mu \mathrm{m}$ and $10 \mathrm{~mm}$, respectively. Specimens with absorbed hydrogen were made by electrochemical charging in $0.5 \mathrm{M} \mathrm{H}_{2} \mathrm{SO}_{4}+1.4 \mathrm{~g} / \mathrm{L}$ thiourea $\left(\mathrm{H}_{2} \mathrm{NCSNH}_{2}\right)$, the liquid temperature being kept at $300 \mathrm{~K}$. Electrochemical charging was carried out under conditions of a current density of about $37 \mathrm{~A} / \mathrm{m}^{2}$ for 2 or 8 hours. The microstructure was observed with an optical microscope and the phase state was confirmed by Xray diffraction with $\mathrm{Cu}-\mathrm{K} \alpha$ radiation. The depth profile of the absorbed hydrogen was analyzed using a glow discharge optical emission spectrometer (GDOES, J-5000RF, Horiba).

\section{Results and Discussion}

Figure 1 shows microstructures in the surface of pre-charged specimens observed with an optical microscope for melt-spun ribbon of $\mathrm{Ni}_{36} \mathrm{Nb}_{27} \mathrm{Zr}_{37}$ on the roller side (a) and on the free side (b). Here, the roller side means the side in contact with the roller during the melt-spinning and the free side is the outer side of the ribbon. The morphology of the surface on these sides is completely different. The surface on the roller side is flat and has many voids. The free side is shinier than the roller side, and also exhibits concavity and convexity of the surface. It is generally known that the cooling rate is strictly different between the roller side and the free side. The morphology of each side does not change so much between before and after electrochemical charging for hydrogen absorption.

X-ray diffraction (XRD) patterns of the melt-spun ribbon for $\mathrm{Ni}_{36} \mathrm{Nb}_{27} \mathrm{Zr}_{37}$ and those of specimens electrochemically charged for 1 or 8 hours with a current density of about $37 \mathrm{~A} / \mathrm{m}^{2}$ are indicated in figures. Figure 2(a) and Figure 2(b) are observed XRD patterns on the roller side and on the free side, respectively. Halo-type diffraction patterns are observed, indicating the amorphous state although tiny peaks are confirmed for the specimens with electrochemical charging. In the case of Lanthanoid-based amorphous alloys, such as ( $\mathrm{La}, \mathrm{Ce}$ )-Co-Al, it has been confirmed that the sample surface was crystallized after hydrogen charging [10]. No shift of the main peak around at 40 degree was confirmed. In previous studies of Ni-Nb-Zr melt-spun ribbons with electrochemical changing, a slight peak shift was observed depending on the amount of the absorbed hydrogen [9]. In the present specimens, it is expected that the amount of absorbed hydrogen did not change so much depending on the charging time. 


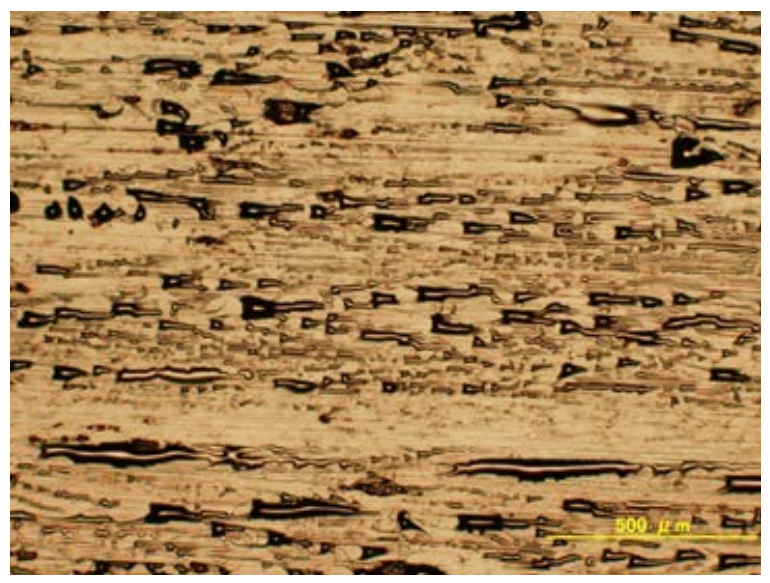

(a)

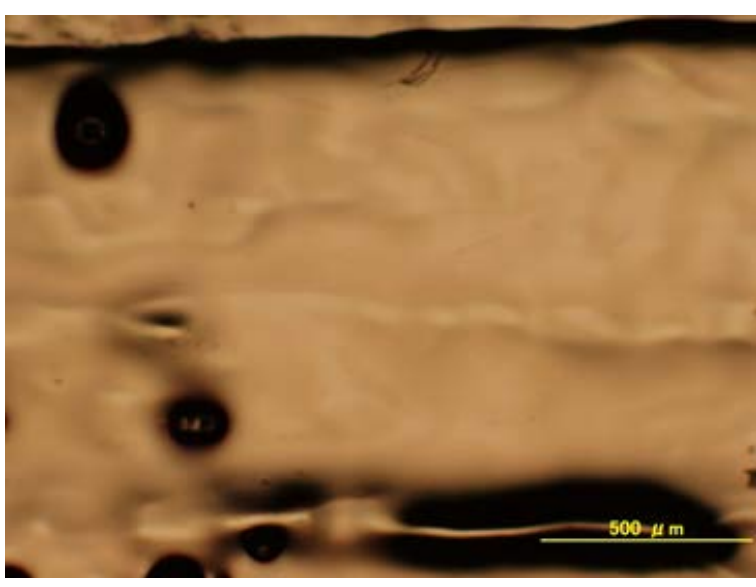

(b)

Figure 1. Microstructures observed with an optical microscope for $\mathrm{Ni}_{36} \mathrm{Nb}_{27} \mathrm{Zr}_{37}$ melt-spun ribbon on the roller side (a) and on the free side (b).

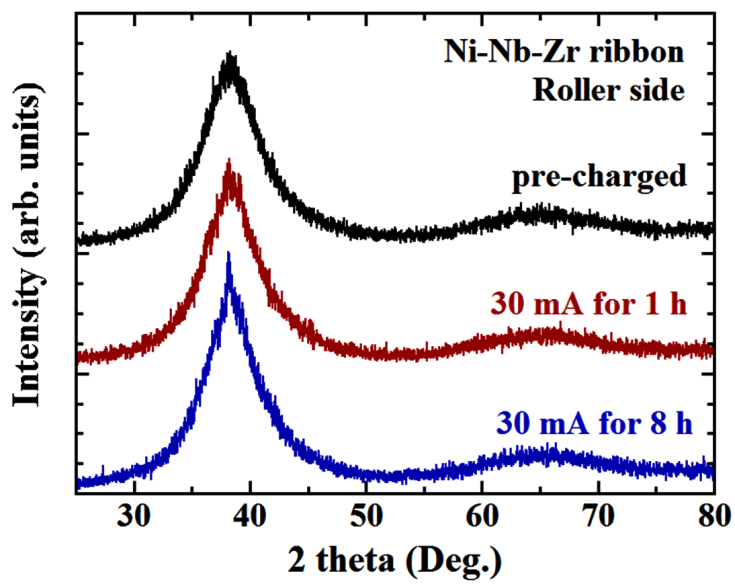

(a)

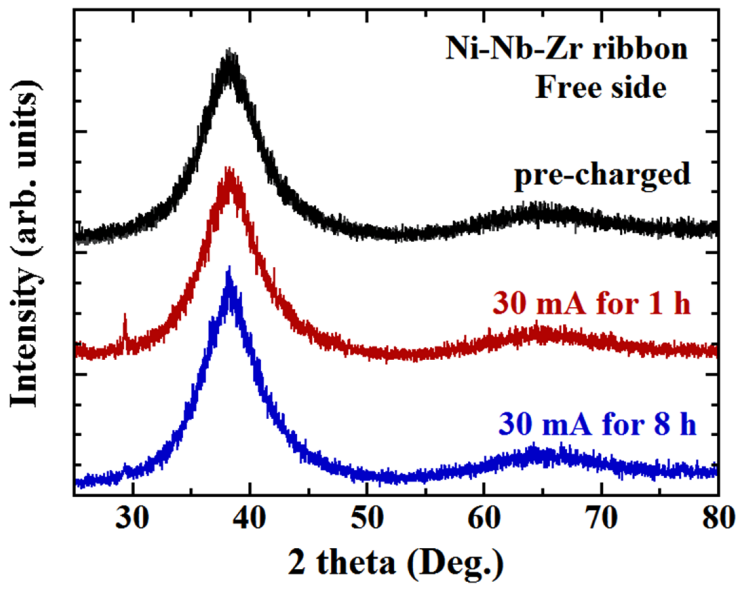

(b)

Figure 2. X-ray diffraction patterns of melt-spun ribbon for $\mathrm{Ni}_{36} \mathrm{Nb}_{27} \mathrm{Zr}_{37}$ and electrochemically charged specimens for 1 and 8 hours with a current density of about $37 \mathrm{~A} / \mathrm{m}^{2}$ on the roller side (a) and on the free side (b).

Figures 3(a)-(f) show depth profiles for the light elements, together with those for $\mathrm{Ni}$, $\mathrm{Nb}$ and $\mathrm{Zr}$ elements for melt-spun $\mathrm{Ni}_{36} \mathrm{Nb}_{27} \mathrm{Zr}_{37}$ amorphous ribbons obtained by the electrochemical charging for 0,2 and 8 hours on the roller side (a)-(c) and on the free side (d)-(f), respectively. It is said that some kinds of light element impurities are basically exist in the surface. Especially, amounts of oxygen and carbon are comparatively large, although they decay with depth. It is clarified that there is a considerable amount of oxygen impurity on the free side. The hydrogen is also contained in the surface of the as-charged ribbons of (a) and (d), and remains at a depth compared with other light elements in (b), (c), (e) and (f). The hydrogen is the absorbed one by electrochemically charging, and the actual amounts will be discussed in later. In order to focus on the composition of $\mathrm{Ni}, \mathrm{Nb}$ and $\mathrm{Zr}$ elements, the numerical values of these elements, which are obtained from the results in Figure 3 as normalized as the total value while becomes 100 at\%, are indicated in Figures 4(a)-(f).

Compositions of the three elements on the surface considerable deviate from the nominal compositions, and the amount of $\mathrm{Zr}$ is significantly rich. Furthermore, behavior of the composition distribution is different between the roller side and the free side, that is, the content of the $\mathrm{Zr}$ element is greater on the free side than that on the roller side. However, the distributions do not change so much after electrochemical charging. These conditions are similar to the reported ones by Kawashima et al. by X-ray photoelectron spectroscopy (XPS) analyses [6]. They also investigated the surface composition of $\mathrm{N}_{36} \mathrm{Nb}_{24} \mathrm{Zr}_{40}$ amorphous ribbon by XPS and concluded that the surface composition of the alloy after hydrogenation was almost the same as that of the pre-charged 


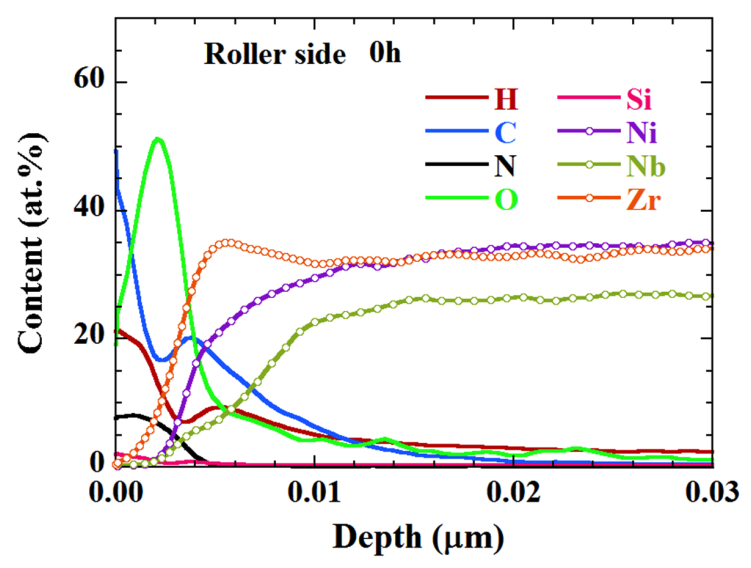

(a)

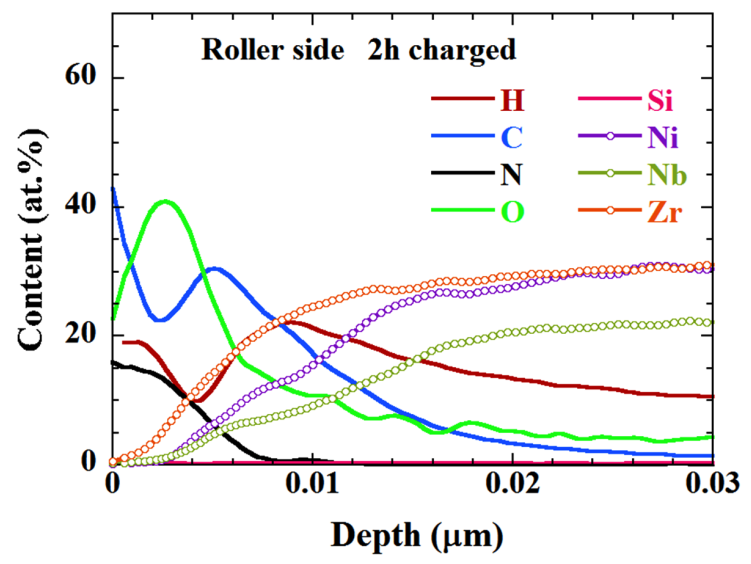

(b)

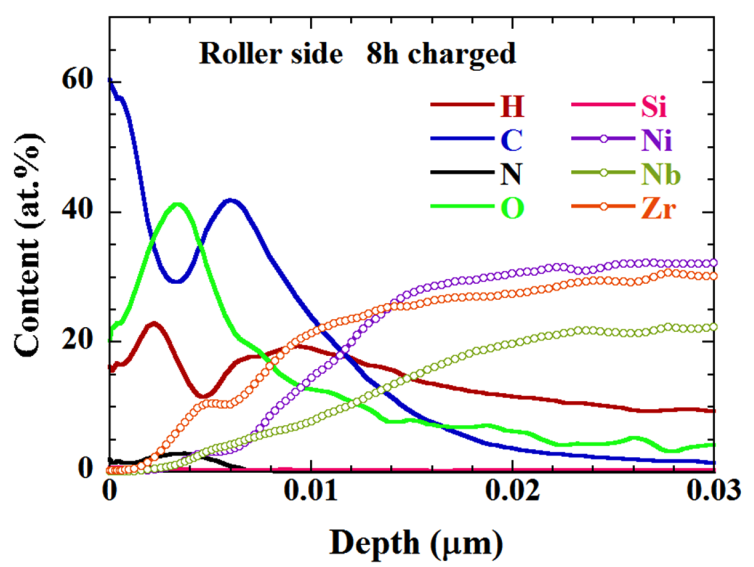

(c)

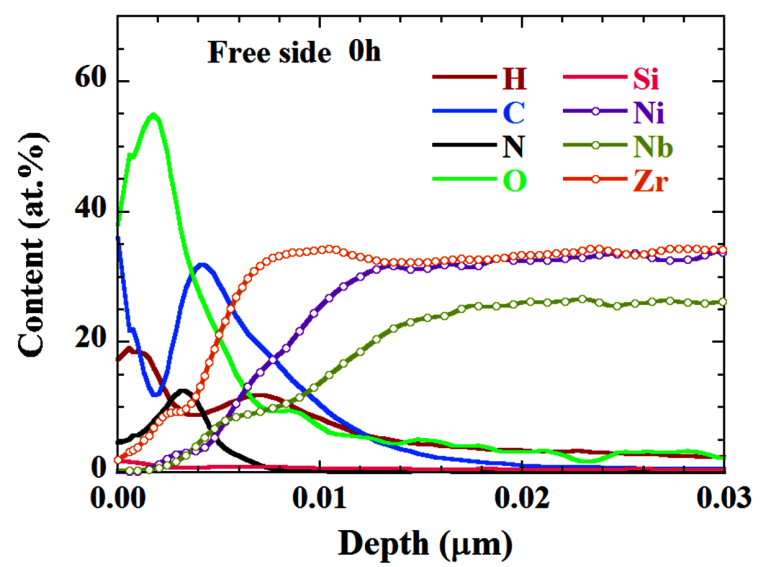

(d)

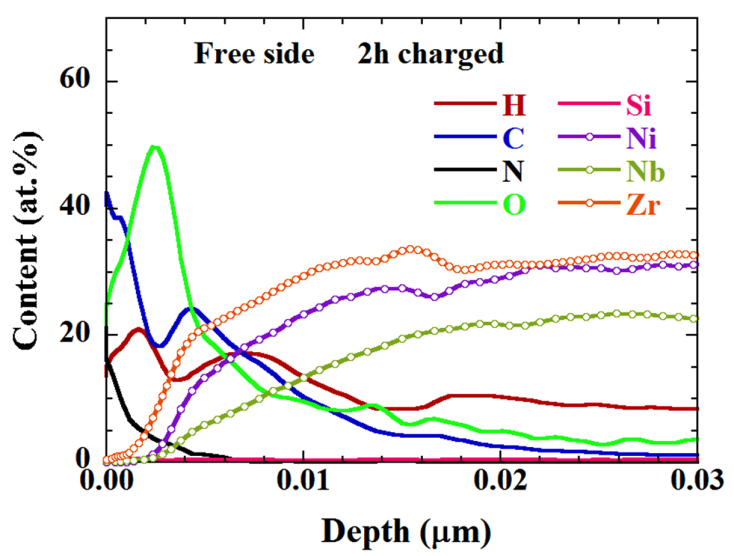

(e)

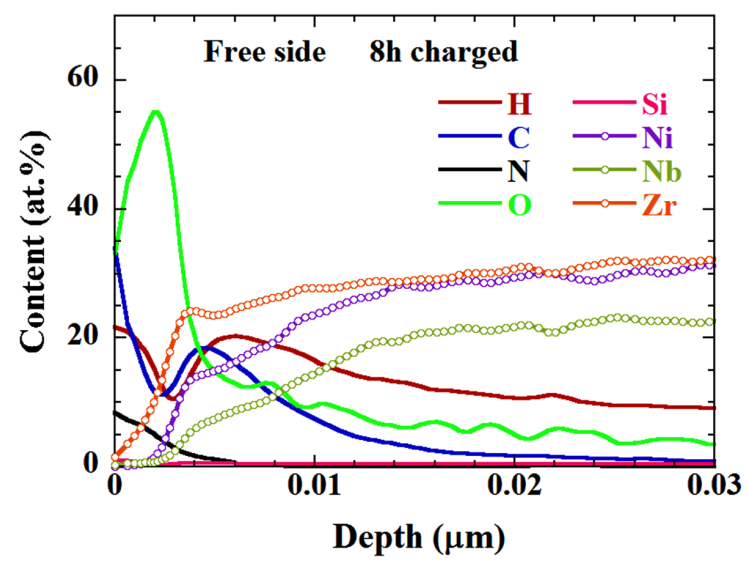

(f)

Figure 3. Depth profiles for the light elements, together with those for $\mathrm{Ni}$, $\mathrm{Nb}$ and $\mathrm{Zr}$ elements for the melt-spun $\mathrm{Ni}_{36} \mathrm{Nb}_{27} \mathrm{Zr}_{37}$ amorphous ribbons obtained by the electrochemically charging for 0, 2 and 8 hours in the roller side (a)-(c) and in the free side (d)-(f), respectively.

specimen and that the $\mathrm{Zr}$ content on the free side surface was larger than that on the roller side [6]. The difference of the compositions between the free side and the roller side would originate from the difference of the cooling rate in the melt-spun technique.

Figure 5(a) and Figure 5(b) are depth profiles of the absorbed hydrogen of the melt-spun $\mathrm{Ni}_{36} \mathrm{Nb}_{27} \mathrm{Zr}_{37}$ amorphous ribbon obtained by electrochemical charging for 0,2 and 8 hours on the roller side (a) and on the 


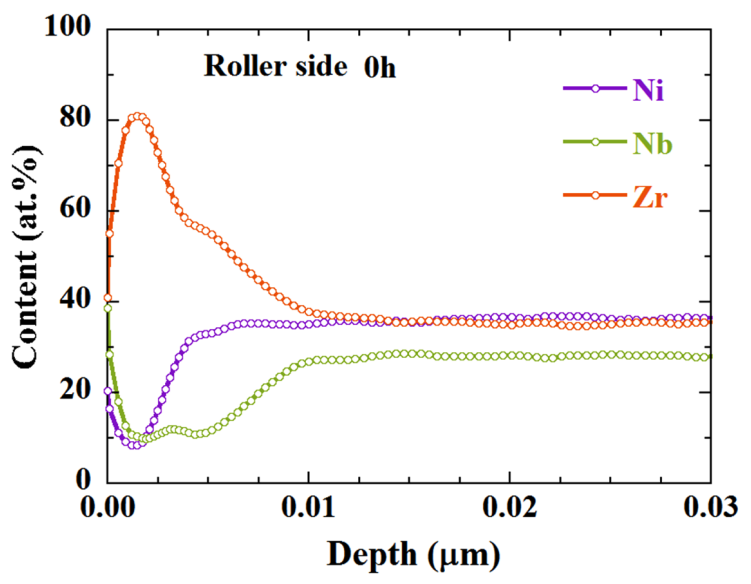

(a)

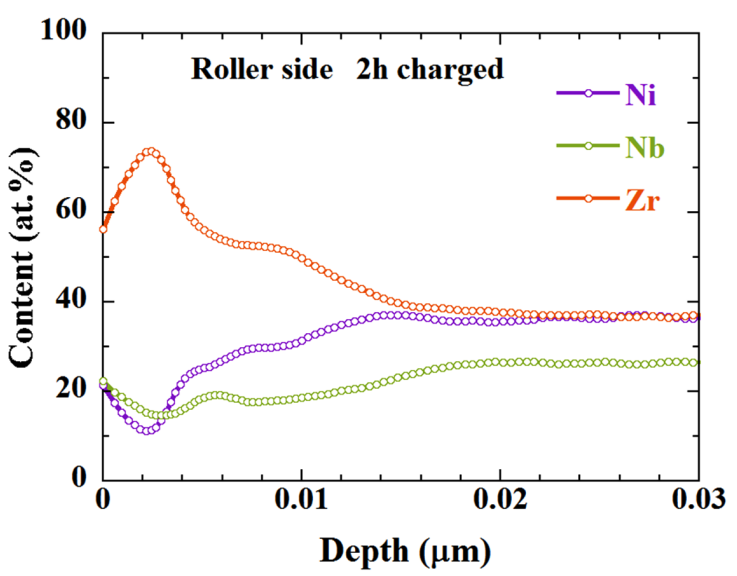

(b)

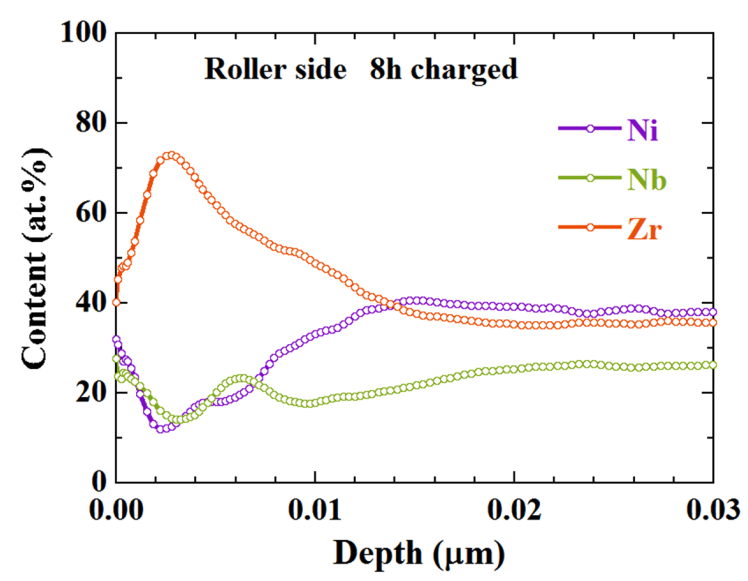

(c)

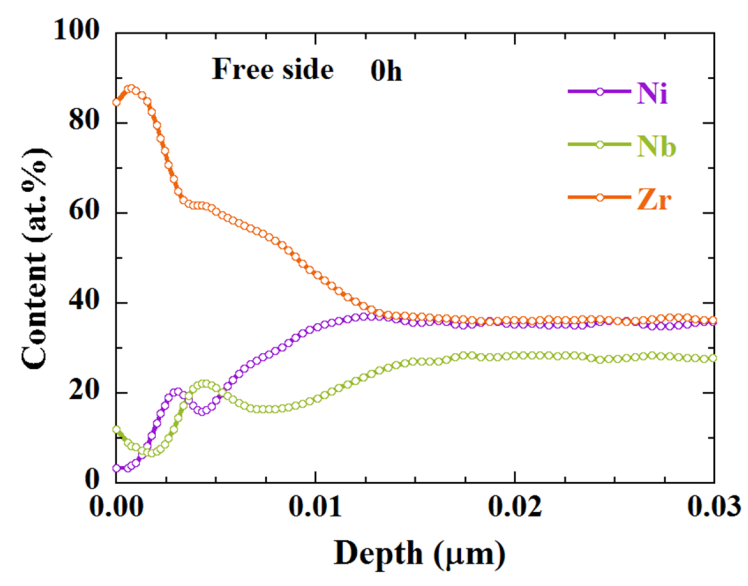

(d)

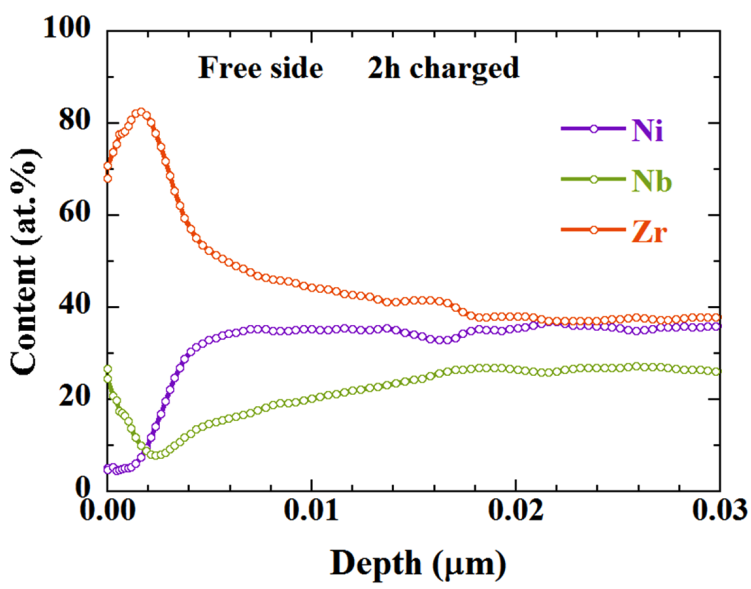

(e)

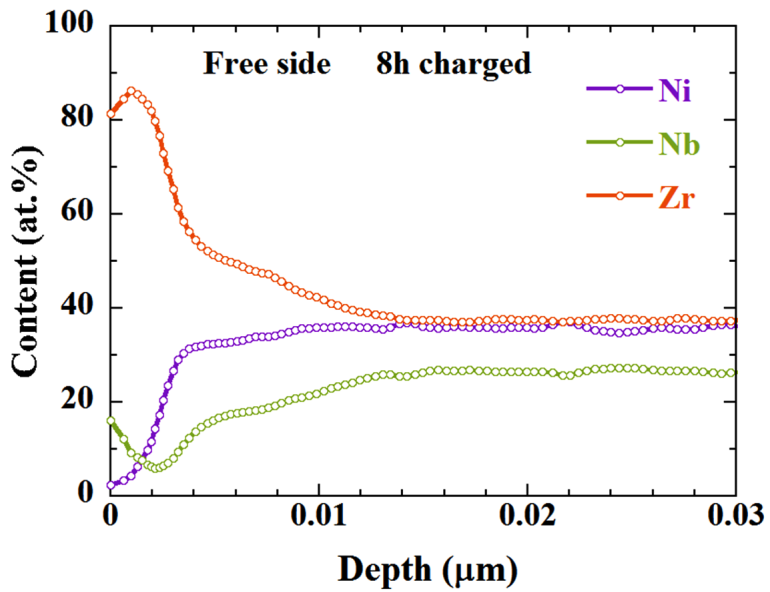

(f)

Figure 4. Depth profiles of the $\mathrm{Ni}, \mathrm{Nb}$ and $\mathrm{Zr}$ elements for the melt-spun $\mathrm{Ni}_{36} \mathrm{Nb}_{27} \mathrm{Zr}_{37}$ amorphous ribbons obtained by the electrochemically charging for 0,2 and 8 hours on the roller side (a)-(c) and on the free side (d)-(f), respectively. The numerical values are obtained from the figures 3 and are normalized as the total value becomes 100 at $\%$.

free side (b). They were simply extracted from the results in Figure 3. As mentioned above, although some amount of hydrogen as an impurity is already contained in the ribbon specimens before electrochemical charging, it is clear that a greater amount of hydrogen is actually absorbed by charging. The differences between the 


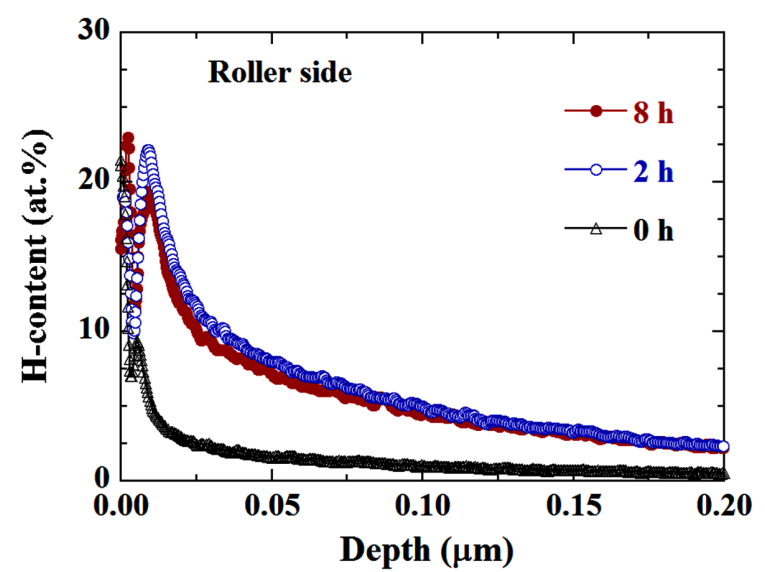

(a)

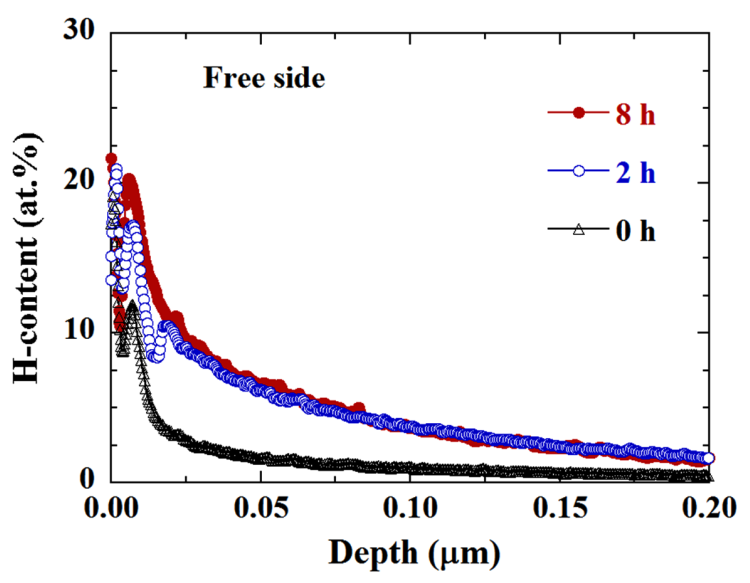

(b)

Figure 5. Depth profiles of the absorbed hydrogen of the melt-spun $\mathrm{Ni}_{36} \mathrm{Nb}_{27} \mathrm{Zr}_{37}$ amorphous ribbons obtained by electrochemica charging for 0,2 and 8 hours on the roller side (a) and on the free side (b).

depth profiles of the hydrogen content for $\mathrm{Ni}_{36} \mathrm{Nb}_{27} \mathrm{Zr}_{37}$ amorphous ribbons by electrochemical charging for 8 hours and 0 hour $(8 \mathrm{~h}-0 \mathrm{~h})$, and 2 hours and 0 hour $(2 \mathrm{~h}-0 \mathrm{~h})$ are indicated in Figure 6 . These profiles are real depth profiles of the absorbed hydrogen in the amorphous ribbons. It is thought that their amount does not depend on the charging time, that is, it seems to be saturated already after charging for 2 hours. However, it is significantly sensitive to depth. The content of the absorbed hydrogen in the surface on the roller side is about 17 at\%, whereas it decays to several atomic percent inside the ribbon. The content of the absorbed hydrogen in the surface on the free side is about 10 at\%, smaller than that on the roller side. The difference of the amount of absorbed hydrogen between on the free side and on the roller side would be due to the difference of the $\mathrm{Zr}$ content in the surface, as mentioned before. Kawashima et al. have investigated electrochemical polarization behavior of amorphous Ni-Zr alloys and concluded that the alloys with lower Zr content show higher cathodic activity, meaning higher hydrogen absorption rate [11]. The surface conditions in the present results are consistent with the previous results reported by Kawashima et al. although the alloy compositions of the amorphous ribbons are slightly different [6]. However, the depth profile of the absorbed hydrogen was investigated for first time in the present study, and it was clarified that the distribution of the absorbed hydrogen was not constant.

Recently, electrochemical methods have been used to investigate the diffusion coefficient. For example, Wen et al. discussed the diffusion coefficient of LiAl obtained by different approaches, such as the potentiostatic, galvanostatic, potentiometric, and steady-state ac methods, and showed that the results obtained by the different methods were in good agreement [12]. Sundaram et al. determined the diffusion coefficient of the hydrogen in some Ti-Al alloys by the galvanostatic mode [13]. They measured the electrode potential as a function of time with respect to a standard hydrogen reference electrode. The diffusion coefficient of the hydrogen in the present study cannot be precisely discussed because of the lack of the systematic investigation. It is expected roughly to be on the order of $10^{-7} \mathrm{~cm}^{2} / \mathrm{s}$ under the assumption that the content of the absorbed hydrogen is saturated for 2 hours under the electrochemical charging. Kirchheim et al. have systematically investigated the diffusion coefficient of the hydrogen in $\mathrm{Ni}-\mathrm{Zr}$ amorphous alloys in various compositions and reported that for amorphous $\mathrm{Ni}_{65} \mathrm{Zr}_{35}$ alloy at room temperature, it was on the order of $10^{-8} \mathrm{~cm}^{2} / \mathrm{s}$ [14] [15]. They also mentioned that hydrogen diffusivity changes over two or three orders of magnitude depending on the Zr content, which results in a change of the electronic structure and of $\mathrm{H}-\mathrm{H}$ interaction.

\section{Conclusion}

Depth profiles of the hydrogen absorption in the $\mathrm{Ni}_{36} \mathrm{Nb}_{27} \mathrm{Zr}_{37}$ amorphous ribbons were analyzed by means of glow discharge optical emission spectrometry (GDOES) in order to investigate the distribution of absorbed hydrogen in Ni-Nb-Zr amorphous ribbons. From the analyses using GDOES, it was confirmed that the amounts of absorbed hydrogen, impurity oxygen and constituent elements of $\mathrm{Ni}$, $\mathrm{Nb}$ and $\mathrm{Zr}$ depend on the depth. Especially, $\mathrm{Zr}$ content becomes rich in the surface, slightly more on the free side than that on the roller side. The amount of absorbed hydrogen is about 17 at\% at the surface on the roller side and it decreases to several atomic percent. 


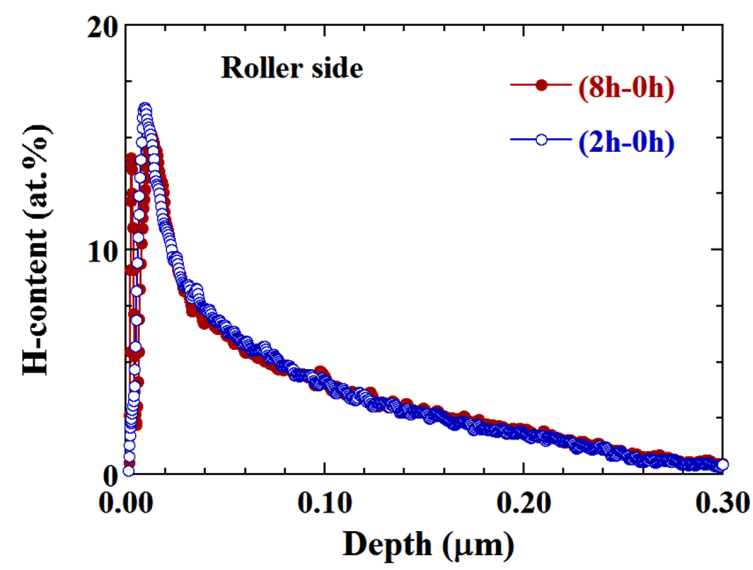

(a)

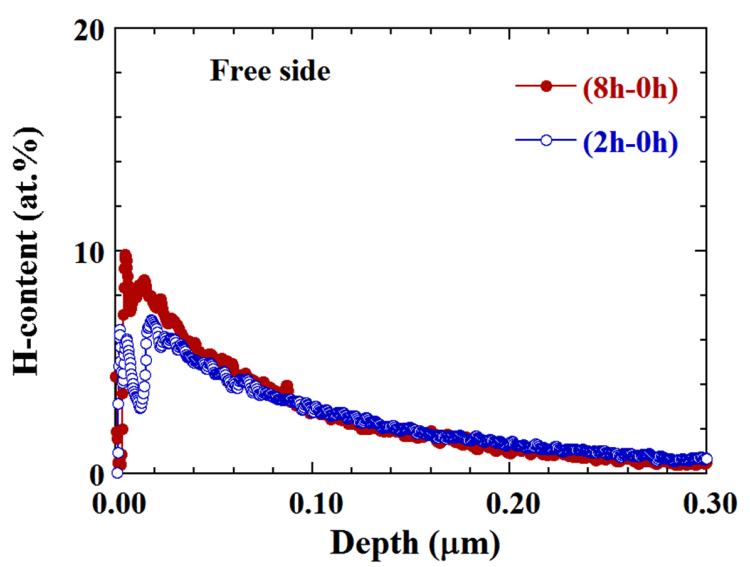

(b)

Figure 6. Difference between the depth profiles of the hydrogen content for $\mathrm{Ni}_{36} \mathrm{Nb}_{27} \mathrm{Zr}_{37}$ amorphous ribbons by electrochemical charging for 8 hours and 0 hour, for 2 hours and 0 hour on the roller side (a) and on the free side (b).

The GDOES analysis clarified that the hydrogen absorbed by electrochemical charging is comparatively welldistributed in the sample surface. The amount of absorbed hydrogen on the roller side tends to be greater than that on the free side, which would correlate with the amount of the $\mathrm{Zr}$ content. These behaviors are similar to the previously reported results of Kawashima et al., even though the composition of the melt-spun ribbon is slightly different. The slight difference of the $\mathrm{Zr}$ content is probably due to the difference of the cooling rate between the free side and the roller side during the melt-spun technique.

\section{Acknowledgements}

The work was supported by a Grant-in-Aid for Science Research in a Priority Area- "Research and Development Project on Advanced Materials Development and Integration of Novel Structured Metallic and Inorganic Materials” from the Ministry of Education, Sports, Culture, Science and Technology, Japan.

\section{References}

[1] Zhang, W. and Inoue, A. (2003) Formation and Mechanical Properties of Ni-Based Ni-Nb-Ti-Hf Bulk Glassy Alloys. Scripta Materialia, 48, 641-645. http://dx.doi.org/10.1016/S1359-6462(02)00469-4

[2] Chen, L.Y., Hu, H.T., Zhang, G.Q. and Jiang, J.Z. (2007) Catching the Ni-Based Ternary Metallic Glasses with Critical Diameter up to $3 \mathrm{~mm}$ in Ni-Nb-Zr System. Journal of Alloys and Compounds, 443, 109-113. http://dx.doi.org/10.1016/j.jallcom.2007.02.114

[3] Kimura, H., Inoue, A., Yamaura, S., Sasamori, K., Nishida, M., Shinpo, Y. and Okouchi, H. (2003) Thermal Stability and Mechanical Properties of Glassy and Amorphous Ni-Nb-Zr Alloys Produced by Rapid Solidification. Materials Transactions, 44, 1167-1171. http://dx.doi.org/10.2320/matertrans.44.1167

[4] Yamaura, S., Shimpo, Y., Okouchi, H., Nishida, M., Kajita, O., Kimura, H. and Inoue, A. (2003) Hydrogen Permeation Characteristics of Melt-Spun Ni-Nb-Zr Amorphous Alloy Membranes. Materials Transactions, 44, 1885-1890. http://dx.doi.org/10.2320/matertrans.44.1885

[5] Yamaura, S., Sakurai, M., Hasegawa, M., Wakoh, K., Shimpo, Y., Nishida, M., Kimura, H., Matsubara, E. and Inoue, A. (2005) Hydrogen Permeation and Structural Features of Melt-spun Ni-Nb-Zr Amorphous Alloys. Acta Materialia, 53, 3703-3711. http://dx.doi.org/10.1016/j.actamat.2005.04.023

[6] Kawashima, A., Yamaura, S., Ohtsu, N., Kimura, H. and Inoue, A. (2006) Mechanical Properties of Melt-Spun Amorphous Ni-Nb-Zr Alloys after Hydrogen Charging. Materials Transactions, 47, 1523-1526. http://dx.doi.org/10.2320/matertrans.47.1523

[7] Fukuhara, M., Kawashima, A., Yamaura, S. and Inoue, A. (2007) Coulomb Oscillation of a Proton in a Ni-Nb-Zr-H Glassy Alloy with Multiple Junctions. Applied Physics Letters, 90, Article ID: 203111. http://dx.doi.org/10.1063/1.2739080

[8] Fukuhara, M., Yoshida, H., Koyama, K., Inoue, A. and Miura, Y. (2010) Electronic Transport Behaviors of Ni-Nb-Zr-H Glassy Alloys. Journal of Applied Physics, 107, Article ID: 033703. http://dx.doi.org/10.1063/1.3284207

[9] Umetsu, R.Y., Yoshida, H., Fukuhara, M., Yamaura, S., Sasaki, T., Sekiguchi, T., Saito, M., Mizuno J. and Kawarada, 
H. (2013) Effect of Hydrogen Absorption on Electrical Transport Properties for $\mathrm{Ni}_{36} \mathrm{Nb}_{24} \mathrm{Zr}_{40}$ Amorphous Alloy Ribbons. Materials Transactions, 54, 1339-1342. http://dx.doi.org/10.2320/matertrans.MF201305

[10] Chuang, C.P., Huang, J.H., Dmowski, W., Liaw, P.K., Li, R., Zhang, T. and Ren, Y. (2009) The Effect of Hydrogen Charging on Ln-Based Amorphous Materials. Applied Physics Letters, 95, Article ID: 241901.

http://dx.doi.org/10.1063/1.3266521

[11] Kawahima, A., Yu, W.-P., Zhang, B.-P., Habazaki, H., Asami, K. and Hashimoto, K. (1997) Pitting Corrosion of Amorphous Ni-Zr Alloys in Chloride Ion Containing Sulfuric Acid Solutions. Materials Transactions, JIM, 38, 443-450.

[12] Wen, C.J., Ho, C., Boukamp, B.A., Raistrick, I.D., Weppner, W. and Huggins, R.A. (1981) Use of Electrochemical Methods to Determine Chemical-Diffusion Coefficients in Alloys: Application to "LiAl". International Materials Reviews, 26, 253-268. http://dx.doi.org/10.1179/imtr.1981.26.1.253

[13] Sundaram, P.A., Wessel, E., Clemens, H., Kestler, H., Ennis, P.J., Quadakkers, W.J. and Singheiser, L. (2000) Determination of the Diffusion Coefficient of Hydrogen in Gamma Titanium Aluminides during Electrolytic Charging. ActaMaterialia, 48, 1005-1019. http://dx.doi.org/10.1016/S1359-6454(99)00431-0

[14] Kirchheim, R. (1988) Hydrogen Solubility and Diffusivity in Defective and Amorphous Metals. Progress in Materials Science, 32, 261-325. http://dx.doi.org/10.1016/0079-6425(88)90010-2

[15] Kirchheim, R., Kieninger, W., Huang, X.Y., Filipek, S.M., Rush, J. and Udovic, T. (1991) Hydrogen in Amorphous Ni-Zr and Ni-Ti Alloys. Journal of the Less Common Metals, 172-174, 880-889.

http://dx.doi.org/10.1016/0022-5088(91)90216-Q 
Scientific Research Publishing (SCIRP) is one of the largest Open Access journal publishers. It is currently publishing more than 200 open access, online, peer-reviewed journals covering a wide range of academic disciplines. SCIRP serves the worldwide academic communities and contributes to the progress and application of science with its publication.

Other selected journals from SCIRP are listed as below. Submit your manuscript to us via either submit@scirp.org or Online Submission Portal.
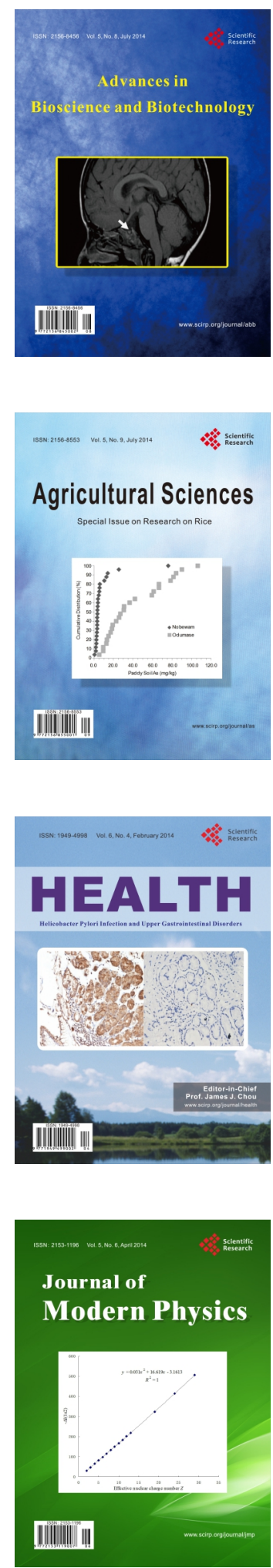
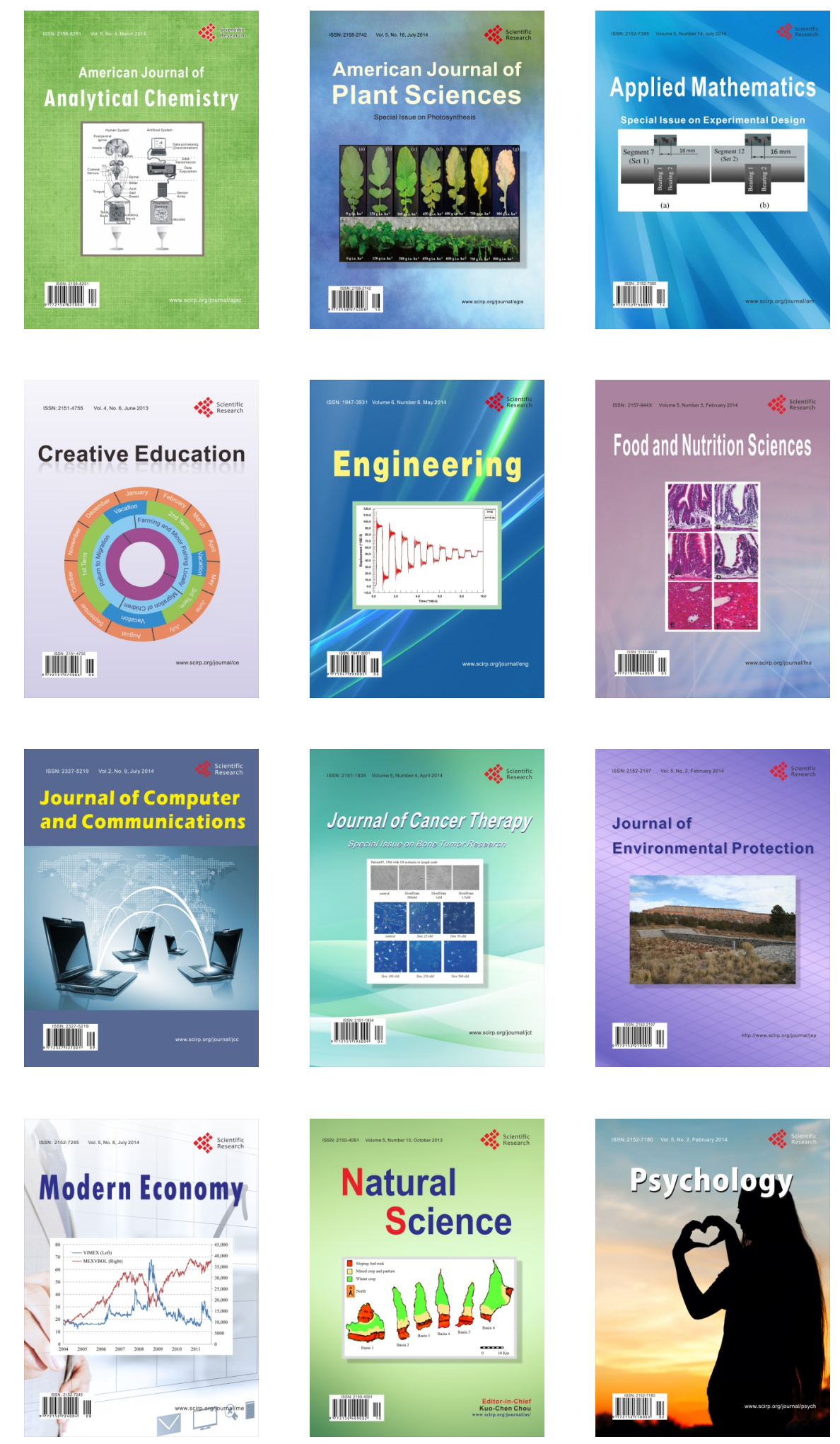